\title{
DEVELOPMENT OF TECHNOLOGY FOR PRODUCTION OF HOT FORGED BRACKETS MADE OF S355 J2 +(N) STEEL BARS
}

\author{
Sveto Cvetkovski* \\ "Ss. Cyril and Methodius University in Skopje, Faculty of Technology and \\ Metallurgy, Ruger Boskovic 16, 1000 Skopje, Republic of Macedonia
}

Received 10.05.2016

Accepted 22.06.2016

\begin{abstract}
Preliminary investigation of forged brackets produced of S355 J2+(N) steel is presented in this research work. Performed investigation was intended to approve predicted production technology. First, all stages in the complex production process chain were defined, starting from the construction of the forging die, heating of the pieces of raw material, preforming, forging of the piece, frying and stress relieving. Confirmation of the proposed production parameters was performed with an application of appropriate computer program DEFORM F3 Ver10.

After performing the forging process, mechanical and microstructural investigations of the produced forging parts were done. These investigations confirmed that preliminary proposed forging process meets all requirements concerning quality of the forged brackets. It means that undesirable forging defects were not detected and mechanical properties (tensile strength and hardness) of the forgings are in accordance with standard requirements.

Key words: Forged bracket, Flowing lines, S355 J2+(N) steel, Tunneling furnace, Forging die

\section{Introduction}

Hot forging is defined as working of a metal above its recrystallization temperature. The main advantage of hot forging is that recrystallization processes dominates over strain hardening during the deformation of metal. Other advantages include: a decrease in yield strength, an increase in ductility, increase of the diffusion processes at elevated temperatures which can remove or reduce chemical inhomogeneity, and the pores may be reduced in size or completely closed during deformation. During processing of steel at elevated temperatures, the weak, ductile,
\end{abstract}

*Corresponding author: Sveto Cvetkovski, sveto@tmf.ukim.edu.mk 
FCC austenite is deformed instead of the strong BCC ferrite which the structure is consist of at lower temperatures. The disadvantages of hot working are: undesirable reactions between the metal and the surrounding atmosphere, less accurate tolerances due to the thermal contractions and warping from uneven cooling, grain structure may vary throughout the metal due to many various reasons [1].

All pure metals and its alloys, with a very few exceptions, are suitable for the deformation by forging. There is a range of more than 2,500 types of steel which can be chosen to be processed with achievement of the most economical production process requirements [2].

In order to determine the best economic solution for the production of high quality parts, development of the forging process begins with part design, and simultaneously consideration of the material selection, process technology, all production stages and die processes.

The part design and process plan make the basis for calculating of the economic efficiency in the project planning stage. This means that the decision to using a forging process has been reasonable and valid. Furthermore, the process plan provides information about the required forging equipment, the die system and the transfer system. These parameters must be considered simultaneously in order to achieve an optimal results $[3,4]$.

Forged products has very important role in the production of steel parts for different applications, but mainly in automotive, airspace and the railway industry. Forging process is implemented in the production of wide range of railway parts like: railway wheels, axle's crankshafts, large and small connecting rods, disk brakes, chassis components, connection couplings, sleeper screws and many others. These parts must fulfill rigorous requirements under exploitation conditions. It means that any type of defects in the forged parts is not allowed $[5,6]$.

Any accident during exploitation means the material damage and more important the possibility of the human injures.

Production of hot forged parts requires expensive equipment and also well educated and experienced personnel too, who can accomplish this complex production process. In this paper complete procedure of the approval of new product manufacturing (forging bracket) starting from the project idea, definition of all steps in technological process and implementing appropriate computer software is presented. Mechanical and microstructural testing of the produced forging parts confirmed that obtained product completely satisfy quality requirements $[7,8]$.

\section{Raw material and forging technology}

\section{Raw material}

In this preliminary research study, hot rolled and normalized steel rods were used as a raw (initial) material. Material quality was S355 J2 (+N) according to EN 10025-12004 standard [9]. Dimensions of the initial material were $\phi 50 \times 6000 \mathrm{~mm}$. Material was marked with number No 1.0570. Chemical composition and mechanical properties of the initial material S355 $\mathrm{J} 2(+\mathrm{N})$ are given in Tables 1 and 2. 
Table 1 Chemical composition of steel S355 J2 (+N)

\begin{tabular}{|c|c|c|c|c|c|}
\hline Element & $\mathrm{C}$ & $\mathrm{Mn}$ & $\mathrm{Si}$ & $\mathrm{P}$ & $\mathrm{S}$ \\
\hline wt.\% & $0.20 \% \max$ & $1.60 \% \max$ & $0.55 \% \max$ & $0.025 \% \max$ & $0.025 \% \max$ \\
\hline \multicolumn{6}{|c|}{ Table 2 Mechanical properties of steel S355 J2 $(+N)$} \\
\hline $\begin{array}{l}\text { Thickness, } \\
\text { mm }\end{array}$ & $\begin{array}{l}\text { Yield strength, } \\
\text { Re, MPa }\end{array}$ & \multicolumn{2}{|c|}{$\begin{array}{l}\text { Ultimate tensile } \\
\text { strength, Rm, MPa }\end{array}$} & $\begin{array}{l}\text { Elongation, } \mathrm{Im} \\
\mathrm{A}, \%\end{array}$ & $\begin{array}{l}\text { mpact toughness, } \\
\mathrm{KV}, \mathrm{J}\left(-20{ }^{0} \mathrm{C}\right)\end{array}$ \\
\hline $3-100$ & $315-355$ & \multicolumn{2}{|c|}{$490-630$} & $\operatorname{Max} 22$ & 27 \\
\hline
\end{tabular}

Definition of forging technology

After the choice of the base material for production of forged bracket i.e. hot rolled rods from $\mathrm{S} 355 \mathrm{~J} 2+\mathrm{N}$ steel, the rods were cut on the mechanical saw to obtain raw pieces with dimensions $\phi 50 \times 210 \mathrm{~mm}$ (weight about $2.582 \mathrm{~kg}$ ). Close die forging process was performed with halved die produced using UTOP EX2 tool steel (DIN 56NiCrMoV7, WNo 1.2714) [10]. Distance between upper and lower half was $2 \mathrm{~mm}$ in order to enable the excess of material to leave the closed die, as illustrated in Figure 1 (a and $b$ ).

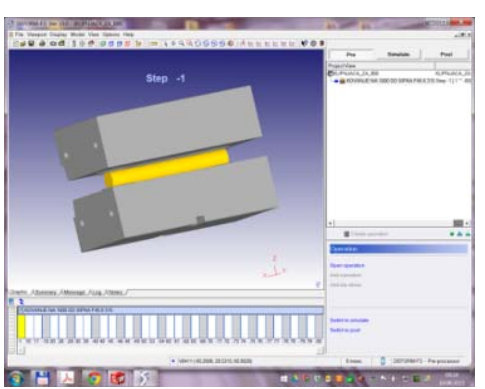

$a$

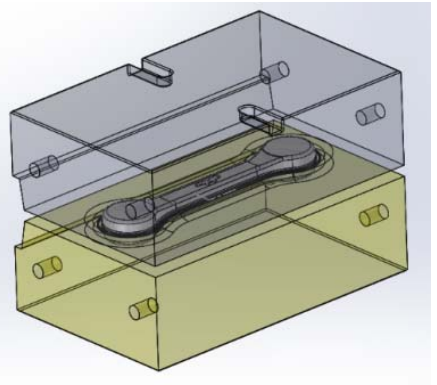

$b$

Fig. 1. (a, b) Halved forging die.

This material is suitable for production of the dies intended for working at high temperatures. Before starting of the forging process the closed dies were heated at temperature $250-350{ }^{\circ} \mathrm{C}$. Pieces of raw material were heated in the induction tunneling furnace at temperature $950-1150{ }^{\circ} \mathrm{C}$, about 40 seconds for each piece (Figure 2a). 


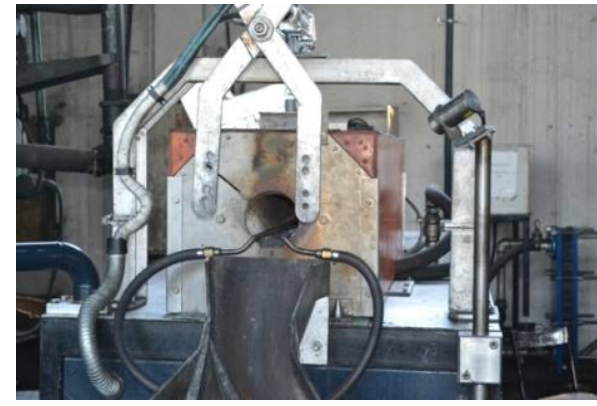

$a$

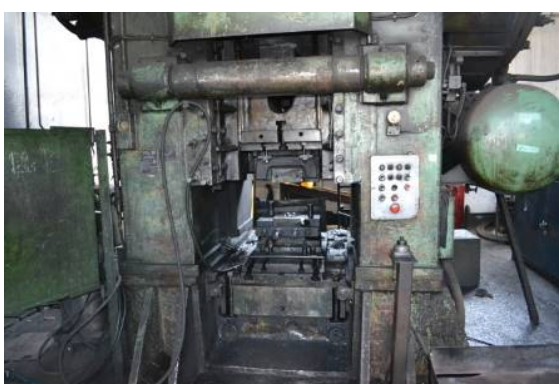

$c$

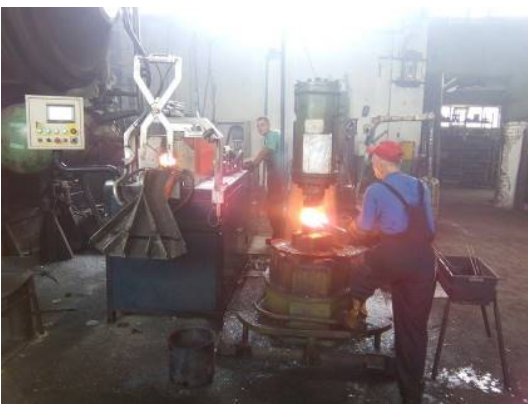

$b$

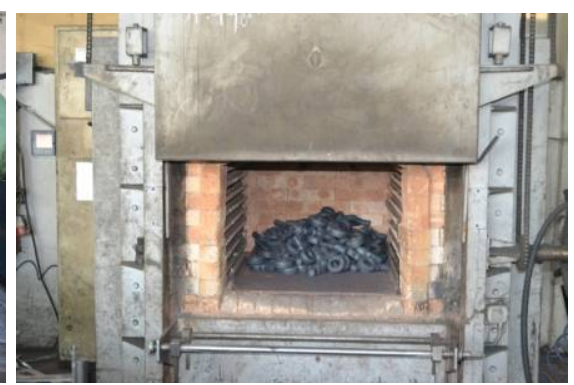

$d$

Fig. 2. (a-d) Forging technology for production of steel bracket.

After taking the pieces from the furnace, they were performed using air hammer (figure 2b). In this way beside preforming, oxide layer is crushed too. For final forging of pieces a 1600 t press was used (Figure 2c). Next step was fraying of excess material with special knifes. Forged parts were heat treated (stress relieving) in the electric furnace at $650{ }^{\circ} \mathrm{C} / 2 \mathrm{~h}$ (Figure $2 \mathrm{~d}$ ). After interrupt the heating pieces were cooled down in the furnace. Final step was shot blasting of forging surface. In order to check the temperature of heated parts, thermo vision camera Raytek (Raynger 3i) was used. It was possible to perform accurate measurements of predicted temperatures (Figure 3). This forging technology predicts welding repairing of defects after their removing from the surface of bracket.

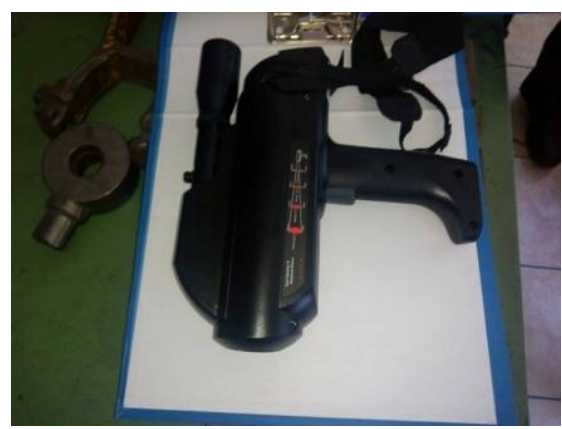

Fig. 3. Thermo vision camera Raytek (Raynger 3i). 
Preliminary obtained values of parameters were checked by computer program DEFORM F3 Ver10. The most important information obtained from this simulation was the ability of predicting of the material flow in the die as well as predicting of the ability of raw material to fill completely the space inside the forging die.

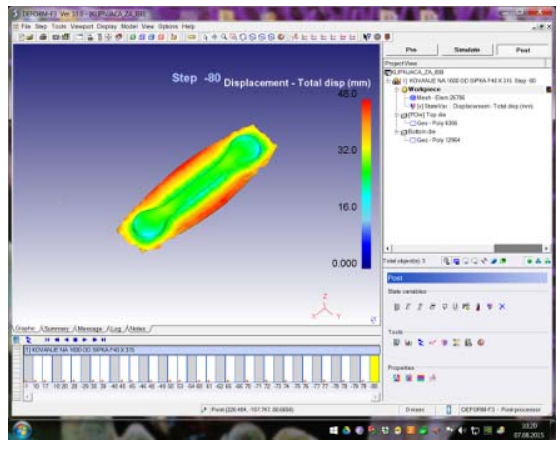

$a$

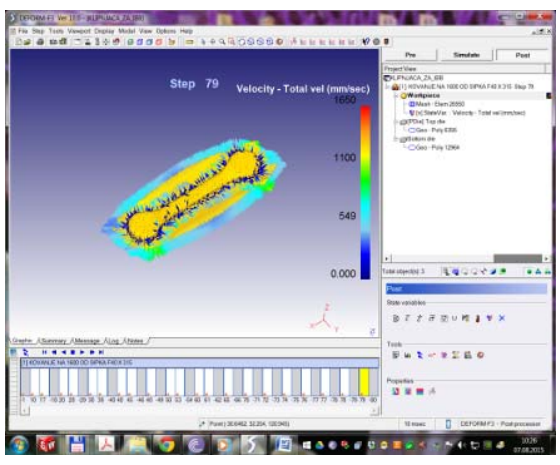

c

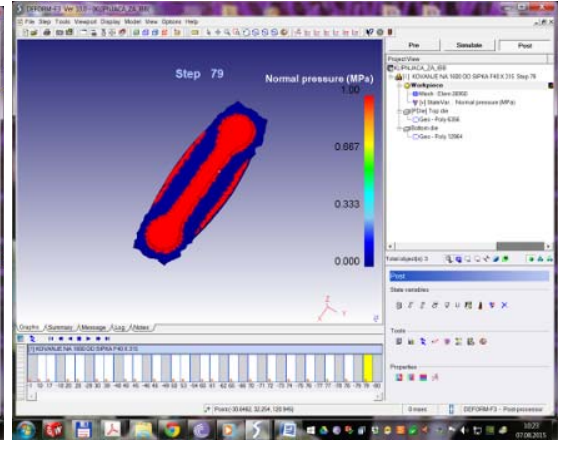

$b$

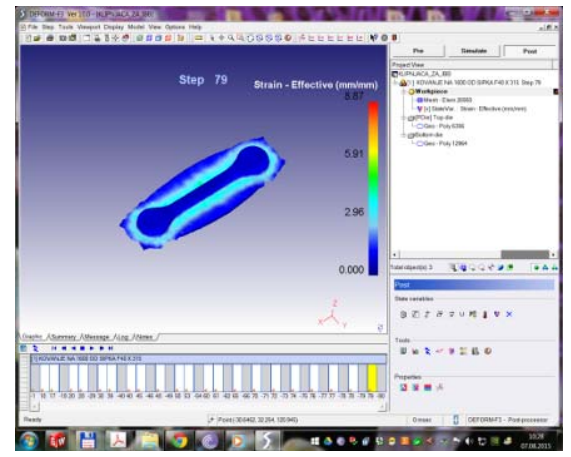

$d$

Fig.4. (a-d) Some important data obtained using computer program DEFORM F3 ver10.

Besides, this program provided the information about displacement of raw material during forging in closed die (Figure 4a), nominal pressure in MPa (Figure 4b), velocity of material flow in different regions (Figure 4c) and effective strain of the piece during deformation (Figure 4d).

\section{EXPERIMENTAL WORK}

After finishing the production process of the forged bracket, different investigations were done in order to check the quality of the finished product i.e. forged bracket. First, a visual control was performed and undesirable surface defects were not detected. Dimensional control satisfied standard requirements too. Penetrant testing was performed for surface defects determination and ultrasound testing for volume defects inside the forging part. In both cases undesirable defects were not found.

Next step was metallographic analysis. For performing metallographic investigations, forging bracket was cut longitudinally in order to obtain two equal parts. 
One of them was taken for metallographic preparation. Because, the part was very long, it was cut in four pieces which were prepared separately (Figure 5). Standard metallographic preparation was done. After grinding at different abrasive papers and polishing with diamond paste, chemical etching was done to reveal the microstructure.

Analysis of nonmetallic inclusions was performed on the polished surface of the specimens using magnification of $\times 100$ (Figure 6). Automatic analysis with VideoMetalTest software confirmed our assumption that sulfides and oxides are presented (Figure 7). The same software was used to analyze the grain size. Very fine grains of the ferritic/pearlite structure were detected.

The basic idea of macro etching was to reveal the flowing lines in the material as result of forging process [11]. As macro etchant solution of equal parts of HCL and distilled water was used. Macro etched pieces are shown in Figure 5.

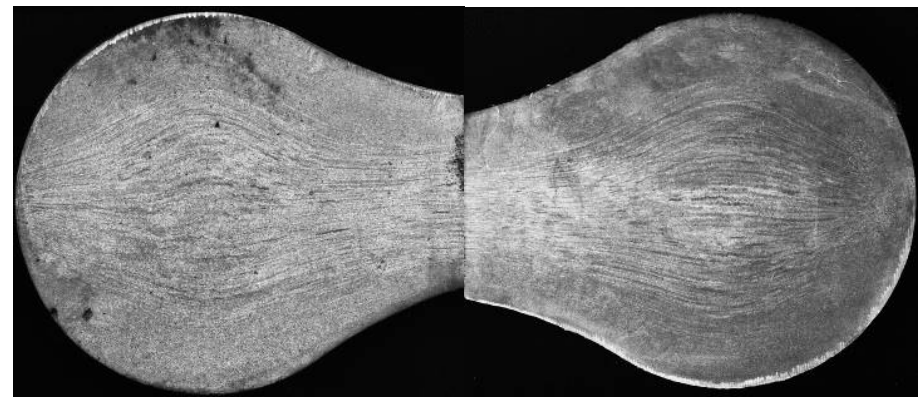

$a(156 H B)$

$b(154 \mathrm{HB})$

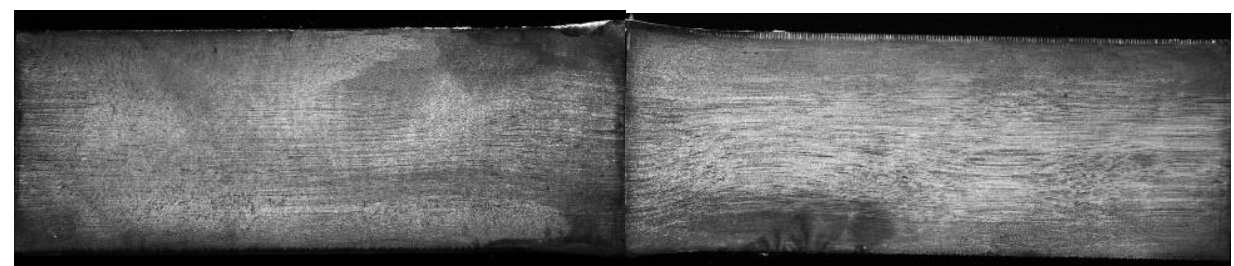

$c(174 \mathrm{HB})$

$d(172 H B)$

Fig. 5. (a-d) Macro etched pieces of forged bracket.

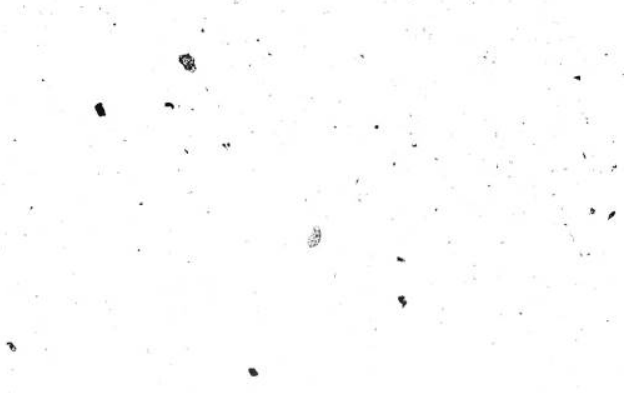

Fig. 6. Nonmetallic inclusions in the initial state of raw material, $x 100$. 


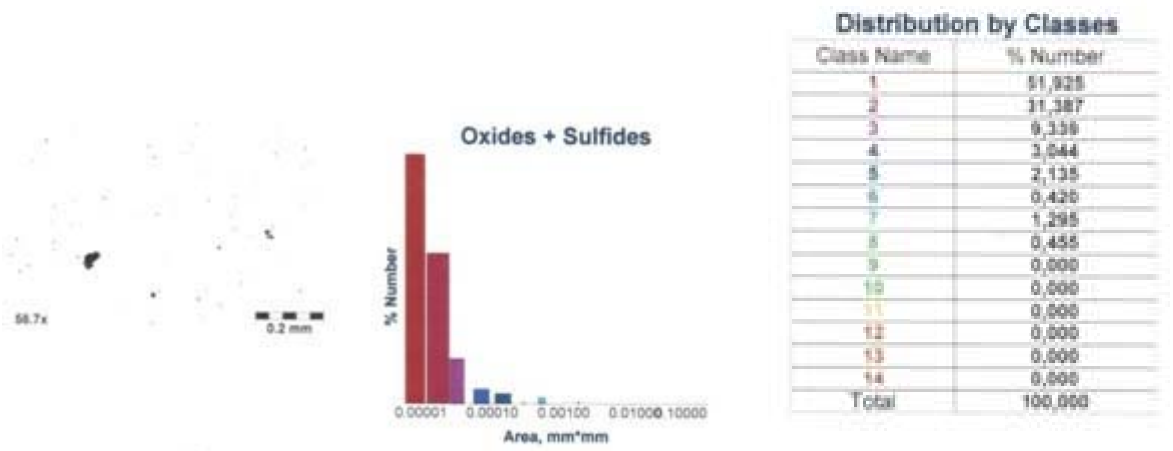

Fig. 7. Automatic micro analyses of nonmetallic inclusions - VideoMetalTest program.

Microstructure of the specimen was revealed by the solution of $\mathrm{HCl}$ and water (Figure 8), and by Nital etching (figure 9) Microstructure consists of ferrite and pearlite. As can be seen from the Figure 8 the elongation of inclusions during the forging of the bracket occurred. These elongated inclusions are sulphides which are soft and plastic.

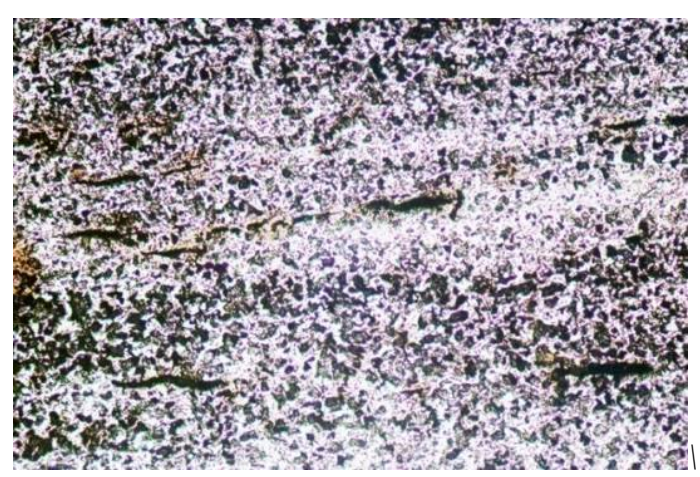

Fig. 8. Microstructure of bracket etched with solution of $\mathrm{HCl}$ and water, $\times 100$.

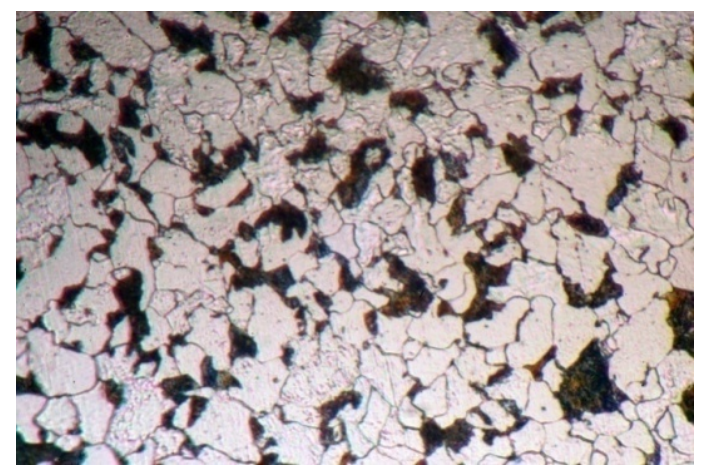

Fig. 9. Microstructure of bracket etched with Nital, $\times 500$. 
Grain size was also determined, using the same software, VideoMetalTest program, as for the $\mathrm{HCl}$ nonmetallic inclusions analysis (Figure 10).
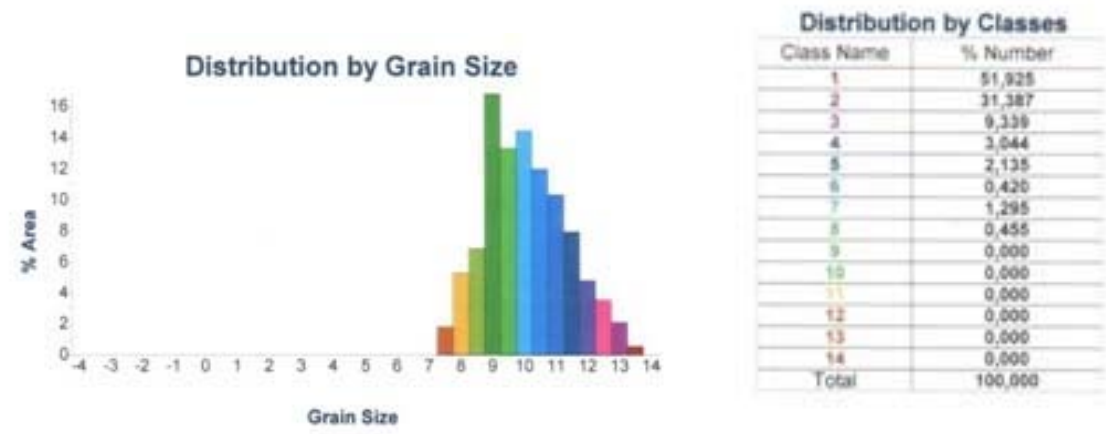

Fig. 10. Automatic determination of grain size using VideoMetalTest program.

For determination of the mechanical properties of forging bracket, tensile specimens were prepared Specimens were machined from the elongated part of the probe (parallel with its longitudinal axis). Position for cutting of the tensile probe is denoted with black strip in Figure 11.

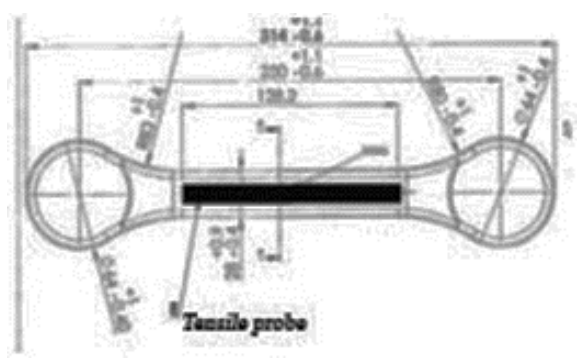

Fig. 11. Position of the tensile probe.

Three tensile specimens were tested and average values of the tensile properties are given in Table 3 .

Table 3 Tensile properties of the forging bracket

\begin{tabular}{cccc}
\hline Material & $\begin{array}{c}\text { Yield strength, Re, } \\
\text { Mpa }\end{array}$ & $\begin{array}{c}\text { Ultimate tensile strength, Rm, } \\
\text { Mpa }\end{array}$ & Elongation, A, \% \\
\hline S355 J2+N & 411 & 501 & 23 \\
\hline
\end{tabular}

Using the metallographic specimens, hardness measurement was performed. There was a difference in the hardness values obtained in the middle region (172 -174 HB) and on the ends of bracket (154 - $156 \mathrm{HB})$. Higher values obtained in the middle part were supposed to be a result of higher deformation during forging. 


\section{Discussion}

According to preliminary defined parameters, a forging of bracket produced from $\mathrm{S} 355 \mathrm{~J} 2+\mathrm{N}$ was performed. Quality of the final product was checked by implementation of different testing methods: visual inspection, dimensional control, penetrant and ultrasound testing which fulfill standard requirements. Performed analysis of nonmetallic inclusions confirmed that oxide and sulfide inclusions were present in the raw material. Fine inclusions, randomly distributed within the structure were also observed. Generally it was shown that the tested material was very clean regarding nonmetallic inclusions. As can be seen from the Figure 7 the elongation of sulfide inclusions was observed after forging of the tested piece.

The crystallographic reorientation of the grains occurred during severe deformation after forging. Besides the alignment of nonmetallic inclusions, a chemical segregation is noticed. As can be seen from the Figure 3, the elongated black lines are found in the microstructure. Obviously pearlitic lines are elongated in this case [12].

Automatic analysis showed that microstructure consists of very fine ferriticpearlitic grains. Their size depends on the forging temperature used for forged bracket production. The ratio between ferrite and pearlite was 70/30. Preliminary forged parameters were given according to the previous experience and computer program DEFORM F3 Ver10.

Macro etching of specimen detects typical flow lines in material. These lines are formed as result of plastic deformation of material during forging of parts. It can be seen from macro photos that flow lines propagate parallel with longitudinal axis of the bracket. So-called partiting lines were not found [13], and undesirable forging defects were not observed in the macro photos.

Investigations of mechanical properties showed that the tested material meets the requirements of EN 10025-1-2004 standard. It has to be pointed out that the forged bracket was stress relieved after forging.

\section{Conclusions}

The results of performed investigations showed that predicted technology for production of the forged steel bracket completely meets the quality requirements, which was confirmed by metallographic investigations and mechanical testing. Mechanical properties are in the standard requirement range, while metallographic and nondestructive testing didn't reveal any undesirable forging defects. According to obtained results it can be concluded that preliminary developed technology can be accepted for serial production of the forged bracket.

\section{Literature}

[1] Schuler Forging, The entire world of forging, Forging the future

[2] Forging Book: The Ultimate Guide of Metal Forging, http://www.gatonbrass.com/metal-forging-guide/

[3] GATONBRASS, Forging Book: The Ultimate Guide of Metal Forging, www.gatonbrass.com/metal-forging-guide/

[4] ASM HANDBOOK, Volume 14, Forming and forging.

[5] NPTEL - Mechanical Engineering, Manufacturing process II, http://nptel.ac.in/downloads/112105127/

[6] Failures Related to Metalworking, www.bzfxw.co 
[7] J. Herian, R. Sulkowski, Quantitative evaluation of the structure and properties of hot rolled products of continuous ingots made of low-carbon steels, Journal of Achievements in Materials and Manufacturing Engineering, Volume 28 Issue 1 May 2008

[8] BS EN 10250-2:2000, Open die steel forgings for general engineering purposes, Part 2 Open steel die forgings for general engineering purposes. Non-alloy quality and special steels

[9] Basedo Steel, DIN 56NiCrMoV7 tool steel

[10] DEUTCHE MASSIVUMFORMUNG, Forgings - Significance, Design, Production, Application,

[11] Pulak M. Metal Forming Processes, http://paniit.iitd.ac.in/ pmpandey

[12] M. KUKURYK ANALYSIS OF DEFORMATION AND DAMAGE EVOLUTION IN HOT ELONGATION FORGING, www.imim.pl/files/archiwum/Vol2_2012/03.pdf

[13] M. G. Cockcroft and D.J.Latham, "Ductility and the Workability of Metals," Journal Institute of Metals, Vol. 96, 1968, pp. 33-39. 